\title{
User Behaviour Analysis of Information Technology in Higher Education
}

\author{
Ratih Hurriyati, Sulastri \\ Faculty of Economic and Business Education, \\ Universitas Pendidikan Indonesia \\ Bandung, Indonesia \\ ratih@upi.edu
}

\author{
Titik Respati \\ Faculty Of Medical \\ Universitas Islam Bandung \\ Bandung, Indonesia \\ titik.respati@gmail.com
}

\begin{abstract}
Information Technology Systems as part of the components of the organization together with human resources, interact with one another. Where in these interactions, there are two potential impacts, the first system to be optimal and the performance become effective as well as an efficient or optimal system becomes human because users of these systems refuse or do not want to use it. Rejection of the information system being developed will have an impact on the low utilization of information systems, which in turn leads to lower returns on investments in information technology. This study aims to gain insight about the user feedback about the attributes of the services offered by the ICT Unit, the level of user satisfaction with the services offered by the ICT Unit and ICT service models that can improve user satisfaction. The research subjects consisted of faculty, students and staff Academician UPI. Total sample of 171 people taken by simple random sampling. Descriptive analysis using frequency distribution and percentage through Likert scale, customer satisfaction index and analysis of important performance analysis. The results showed that the tangible dimension is the dimension that is considered the most important services, and is considered to have the highest performance compared to the dimensions of other services. ICT satisfaction index 61.96 percent, this indicates generally quite satisfied with the service users of ICT, while the result of measurement of each dimension of service shows that reliability dimension has a level of performance that comes closest to the user's expectations is 73.08 percent, In order to improve the satisfaction of users of ICT services is needed improvements to maximize the number of attributes (1) Free access to information, (2) The connection quality systems currently in use, (3) Security when accessing, (4) Completeness of physical facilities UPInet, (5) Free providing services and dealing with customers, (6) hours of services provided ICT Unit, and (7) Staff Unit ICT capability to understand customer need
\end{abstract}

Keywords-ICT, Service Quality

\section{INTRODUCTION}

\section{A. Background}

Law No. 12 of 2012 on Higher Education (UU PT) has set the entire College of State Owned Legal Entity (PT BHMN) as a Legal Entity State Universities (PTn BH). This change in status provides opportunities for seven University PT BHMN status to design the new Statute. The passage of the
Government Regulation No. 15 of 2014 of the Statute of the University education Indonesia

Transformation of University Pendidikan Indonesia (UPI) into PTn BH, university as mentioned through PP No. 15 years 2014, basically was a very strategic policy even the implementation often created some complex problems. PTN BH status made UPI had independence for self-directing, self-motivating, self-regulating, self-supporting, self-assessing and self-decision to respond with a challenge without tied by a rigid regulation and bureaucracy in Central Government, which occurred over the years

The problem was how to play and to position UPI as PTn BH university in the effective way, efficient and had accountability. Answering the challenge was not easy. Paradigm and management strategic changing required from a conventional one into new paradigm and new strategic management, which means the current UPI managements (academic staff, human resources, facilities, financial, technology, public relationship) should be seen as the industrial activity's sector (corporate). The importance to present a corporation paradigm was not only fit with BHMN status but further would facilitate the transformation of either structural or cultural in UPI organization. Within these traditions, measurements such as effectiveness, efficiency, productivity, quality, growth, satisfaction, flexibility, openness and performance assessment and accountability would growth and developed in UPI organization.

Information Technology Systems built by UPI as a component part of the organization together with human resources, interact with each other. In the interaction, there is hope the high acceptance of existing information systems, so that the system will be optimized and the performance will be more effective and efficient. Research in the first year indicates that the use of Internet technology in UPI $h$ is still not optimal. It is affecting the use of infrastructure built with high investment are not optimum. The utilization of the system, and the information would affect the user and the system [1]. The impact upon the user shall determine the individual user satisfaction while the effects of the system will affect the organization.

The effectiveness of the information technology system is characterized by high utilization of system users, in addition 
affected by the level of user acceptance within the system, is also affected by the quality of service provided by the organization.

Provide good-quality service to users will provide customer satisfaction. Customer satisfaction is feeling happy or disappointed by someone as a result of a comparison between the achievements or products received (perceived service) with service expected [2]. Superior (inferior) quality of service associated with a favorable (unfavorable) behavioral intentions, while the favorable (unfavorable) behavioral intentions related to customer retention (defection) and will ultimately affect the (negative) financial consequences positive [3].

The system quality, information quality and service quality independently and together affects both through the use and user satisfaction [4]. If the positive experience gained since using the system will result in higher user satisfaction. High satisfaction will lead to increased interest in using (intention to use) and then will increase usage. Similarly, if a positive net benefit gained will strengthen the interest of users to use the system and improve user satisfaction.

\section{B. Research Purposes and Benefits}

The aim of this study was to obtain a picture of the user feedback on the attributes of the services offered by ICT and the level of user satisfaction for the services offered by ICT. The findings from this study are expected to be a solution in order to develop a model of information system services of the college environment, especially at the Universitas Pendidikan Indonesia, which is capable of increasing the actual use of information systems that invested so eventually able to push the performance of higher education as a whole, comprehensive and sustainable.

\section{STUDY LITERATURES}

\section{A. Service Quality}

Service quality as a measurement of how good a service level given could meet customer expectation [5] [6]. Based on this definition, service quality could be formed by fulfilled customer needs and wants; and delivery accuracies to balance the customer expectation. Parasuraman et.al. mentioned two main factors, which affected service qualities

1. Perception of customers for services received (Perceived service). Quality should start from the needs of consumers and end on customer perception. This shows that the image of good quality is not based upon the viewpoint or perception of service providers, but based on the customer's viewpoint or perception.

2. Actual services expected or desired (expected service); In the context of the quality of services and satisfaction perhaps reached a consensus that, customers' expectations have a large role as a factor of comparison of quality evaluation. .

It based either case. The high level of service quality can be measured by comparing the expected service with perceived service. Olson and Dover in 1998 Fandy Tjiptono, 2008, the expectation of customers is customer confidence before trying or buying a product, which is used as a standard or benchmark in assessing the performance for the product concerned. Each different consumer can apply different types of expectations for different situations

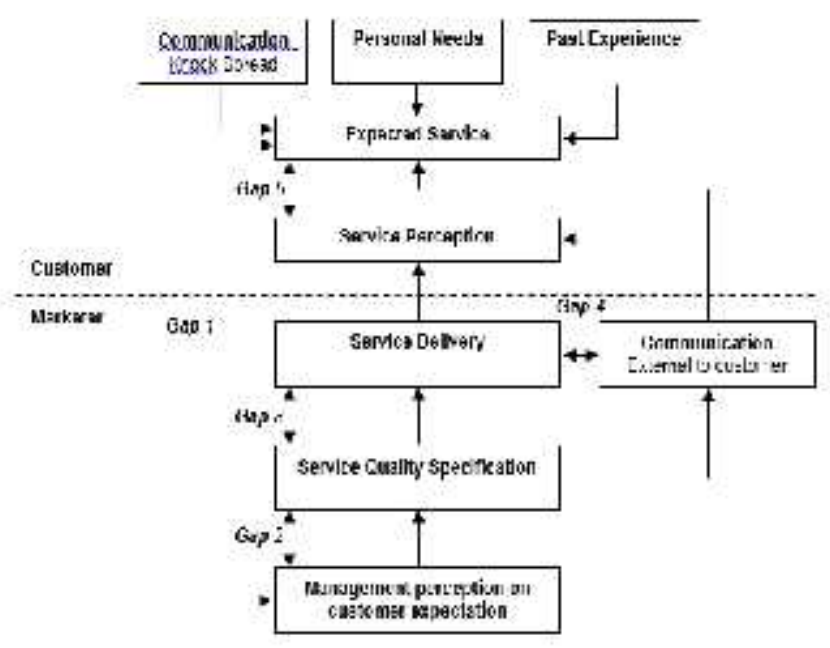

Fig. 1. SERQUAL Conceptual Model

\section{B. Dimension of Service Quality}

Five service quality dimensions [2] [5] [6]:

- Reliability - The ability to perform the promised service dependably and accurately.

- Responsiveness - The willingness to help customers and provide prompt service.

- Assurance - The knowledge and courtesy of employees and their ability to convey trust and confidence.

- Empathy - The provision of caring, individualized attention to customers.

- Tangibles - The appearance of physical facilities, equipment, staff, and communication materials.

\section{Customer Satisfaction}

Satisfaction is a person's feelings of pleasure or disappointment that result from comparing a product or service's perceived performance (or outcome) to expectations [2]. If the performance or experience falls short of expectations, the customer is dissatisfied. If it matches expectations, the customer is satisfied. If it exceeds expectations, the customer is highly satisfied or delighted

It explained that customer satisfaction. In general, was someone's feeling level after compared performance felt with hope. Customer expectation was a respond of perception evaluation differential between early hope before purchasing (or other performance standards) and product actual performance they received after used or consumed the product. From this definition, it could be concluded that basically customer satisfaction was a hope meet expectation perceived by customer 


\section{The Former of Customer Satisfaction Attributes}

Attributes that formed customer satisfaction, known as "The Big Eight" were consisted of [8]:

- Value to Price Relationship, was a relationship between price and product value, which defined by a difference between value received by the customer, and a product produced by a company.

- Product Quality, was quality of all components which formed the product so the product had added value or could give a benefit to their customers.

- Product Features, was physical components from a product that created a benefit.

- Reliability, was a combination of product's ability from a reliable company, so the produced product was in accordingly with company promises or meet customer expectation.

- Warranty, was an offer to return purchasing price or service for the broken product during a condition when the product got damages.

- Respond to and remedy of problems, was the employee attitude in respond to the complaint and helped customers to handle problem occurred.

- Sales Experience, was interpersonal relationship between employee and customer, especially in communication that related with purchasing.

- Convenience of Acquisition, was the easiness provided by the company to their customer for the product they produced.

\section{E. Importance Performance Analysis}

One of the customer satisfaction measurement technique, which often used was Important-Performance Analysis by using importance rating and performance rating. Customer satisfaction measurement could be performed with several purposes, which were.

1. Identified customer requirement (important rating), was aspects that considered important by customer and could affected them, either satisfied or not.

2. Defined customer service level against organization performance on some important aspects.

3. Compared customer satisfaction level against the company with customer satisfaction level against another organization, both direct and indirect competitor.

4. Identify PFI (Priorities for Improvement) through gap analysis and importance score with satisfaction.

5. Measured customer satisfaction index which could became reliable indicator to monitor development progress.
Importance Performance Analysis (IPA) could identify any dimension that needs attention in order to increase service quality. There were two analysis component in IPA, which were quadrant analysis and gap analysis. Through quadrant analysis, customers respond against plotted attributes could be known based on expectation level and the performance of those attributes. Meanwhile, gap analysis was used to see the gap between performances of an attribute with the customer expectation of the attribute

Importance

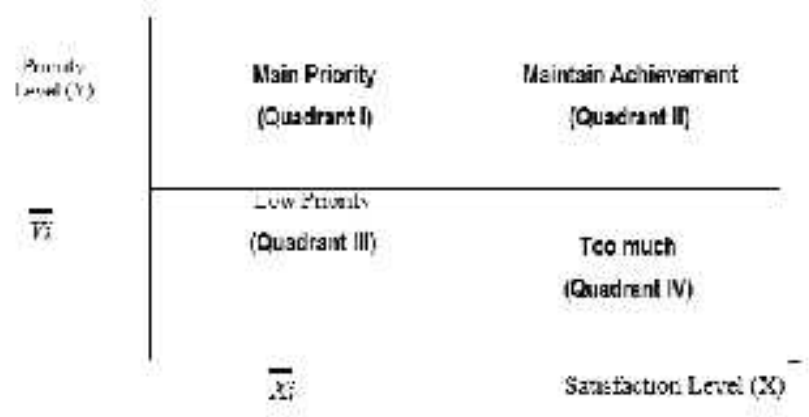

Fig. 2. Importance Perfomnce Analysis Diagram

Diagram above were consisted of four quadrants:

- Quadrant I (Main Priority). This quadrant carried the attributes of service quality of information system which considered important by information system user but in the reality the quality of these attributes were lower than user expectation level. Attributes in this quadrant need improvement so the performance could satisfied the user.

- Quadrant II (Maintained Achievement). These attributes in this quadrant was important and already had a high performance. These attributes was need to be maintained for the next period.

- Quadrant III (Low Priority). Attributes in this quadrant were considered less important by the visitor and in the reality the performance was not special. Improvement of attributes in this quadrant could be reconsidered because the effect of the benefit accepted by user was so little.

- Quadrant IV (Too much). These quadrants contained attributes which considered less important and too much. Performance improvement on these attributes would cause inefficiency resource only.

\section{F. DeLone\&McLean Information System Success Model}

Several models have been developed by some expert to evaluate factors that pushed the success of an information system implementation. One of the famous research was an information system success model as seen on Picture 2.3 [9]. In the early development, D\&M IS success model reflected dependency of six information system success measurement. 
The six or factors models were (1) System quality, (2) Information Quality, (3) Use, (4) User Satisfaction, (5) Individual Impact and (6) Organization Impact [10].

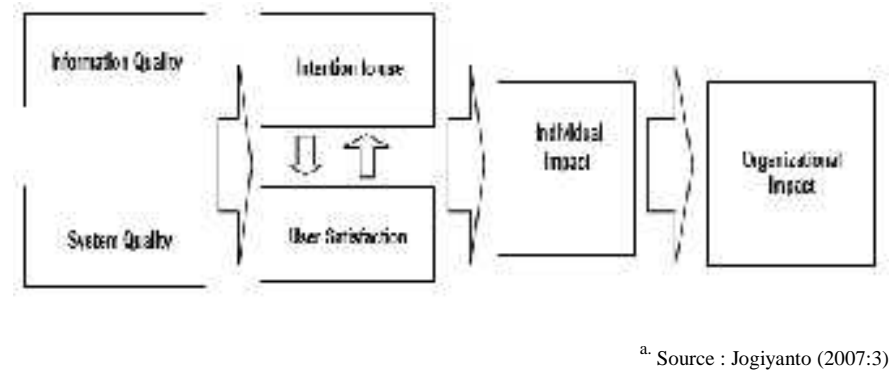

Fig. 3. DeLone\&McLean Information System Success Model

Information System Success Model mentioned above was based on process and causal relationship. That model explained that system quality and information quality was independently and together would affect both utilization and user satisfaction. Utilization volume also affected customer satisfaction both positive or negative. Utilization and customer satisfaction affected individually and later affected the organization.

Based on critics accepted and also based on information technology system and user, DeLone and McLean later renewed the model by. Broaden it as seen on Picture 2.4 [11].

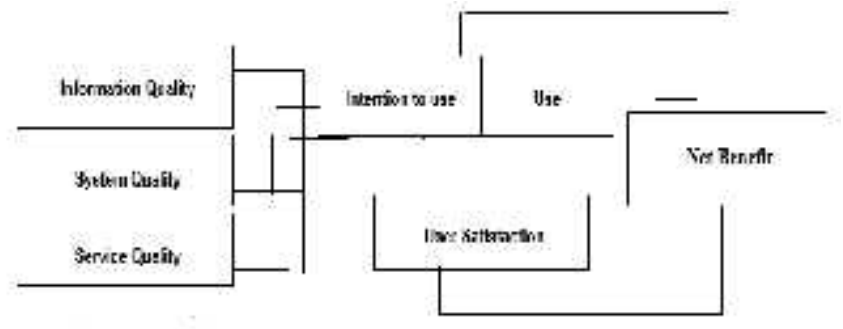

b. Source : Jogiyanto (2007:107)

Fig. 4. DeLone\&McLean Information System Success Model Renewal

In the developed model, there was additional variable that defined information system success, which was service quality and intention to use as an alternative from user dimension. Other than variable additional, there was also a combination of individual impact and organizational into one variable as net benefit

The model above explained that [1]:

- System quality, Information quality and service quality independently and together affected each other both utilization and user satisfaction. Utilization and user satisfaction has close relationship.

- Utilization should be prior customer satisfaction as a process, but positive experience because of the utilization would cause higher customer satisfaction as causal.
- With same way, user satisfaction improvement would cause the increasing of intention to use and later would increase the utilization.

- If net benefit was positive, it would strength user intention to use and also user satisfaction level.

The explanation above shown that quality of an information system was a factor that determined the success of an information system. Based on research aimed, which was to develop information technology service development model to improve user satisfaction, quality variables from a system information and its measurement would be discussed.

\section{G. Information Quality}

Information, was numbered of data, which had been processed through data process procedures in order to test the level of truth, utilization based on it needs. Information quality measured output of an information system. Mentioned [10]: (1) Accuracy, Information could fill information requirement, (2) Currency. Information could fill needs of new information,
(3) Timeliness,
(4) Reliability,
(5) Completeness,

(6) Conciseness, (7) Format, (8) Relevance. Information could fulfill requirement.

\section{H. System Quality}

System was defined as procedures and component approaches. Based on procedures, system was defined as the group of procedures that had certain purposes. Meanwhile from component approach, system was defined as the group of components that connected to each other and created a unity to achieve a certain purpose. .

In relation with information system technology, system information quality could be measured based on (1) Reliability of the computer system, (2) On-line response time and (3) The ease of terminal [12] [13].

\section{Information Service Quality}

The presence of end-user computing (EUC) caused information technology system department was not only as an information provider but also a service provider, so the information system effective measurement was not limited to information quality only but also service quality delivered

According to DeLone and McLean, service quality was part of system quality, but end user roles changing such as manager role changing with EUC role and information technology system changing into the strategic role caused a demand to separated service quality from system quality. It's believed that if service quality was measured in the proper way, this component deserved to be added together with system quality as an information system success component.

Even though service quality could be categorized as a component, in D\&M model, has different weight with information and system quality, depend on the analytical level. If the measured one was the success of single system, information quality and system quality was the most important quality components. However, if the success of whole 
technology system department was measured, service quality probably was the most important component.

\section{J. Information Service Quality Measurment}

Service quality indicator were as below [7] [14] [15] [1] :

1. Listening-Service providers should understand what customers really want through continuous learning about the expectations and perceptions of customers and noncustomers (for instance, by means of a service-quality information system).

2. Reliability-Reliability is the single most important dimension of service quality and must be a service priority.

3. Basic service-Service companies must deliver the basics and do what they are supposed to do-keep promises, use common sense, listen to customers, keep customers informed, and be determined to deliver value to customers.

4. Service design-Service providers should take a holistic view of the service while managing its many details.

5. Recovery-To satisfy customers who encounter a service problem, service companies should encourage customers to complain (and make it easy for them to do so), respond quickly and personally, and develop a problem-resolution system.

6. Surprising customers-Although reliability is the most important dimension in meeting customers' service expectations, process dimensions such as assurance, responsiveness, and empathy are most important in exceeding customer expectations, for example, by surprising them with uncommon swiftness, grace, courtesy, competence, commitment, and understanding.

7. Fair play-Service companies must make special efforts to be fair, and to demonstrate fairness, to customers and employees.

8. Teamwork-Teamwork is what enables large organizations to deliver service with care and attentiveness by improving employee motivation and capabilities.

9. Employee research-Marketers should conduct research with employees to reveal why service problems occur and what companies must do to solve problems.

10. Servant leadership-Quality service comes from inspired leadership throughout the organization; from excellent service-system design; from the effective use of information and technology; and from a slow-to-change, invisible, all-powerful, internal force called corporate culture

A quality usually was not defined by one attribute or single dimension of a product or service, but through some attributes. The quality subjects which applied on information system products and had identified eight different dimension [5]. The dimensions consisted of:

1. Performance, this dimension was about how good an information system did what should be done
2. Features, this is an accessories that completed or increased basic function of information system. For example: input, proses, and output produced.

3. Reliable, this quality dimension was related with the ability of information system to survive during normal use.

4. Compatibility, this dimension was related with how good the information system fit the standard. For industry costumer, company/institution who purchased from other company/institution, the standard usually stated in tight quantitative terms.

5. Durability was economics age of information system and modern technology made this possible. Meanwhile there are many information system products created with one time utilization. It means that the existing information system could not be used if there are system development.

6. Service easiness, information system used for long term need a service or maintenance. Information system designed which made service easiness would add product value. Characteristics of the person who handled the service also became part of the dimension.

7. Aesthetics, quality was not always rely on functional ability. The aesthetics of an information system was rely on how the products was seen and felt, could became important dimension.

8. Quality Perception, this dimension was not only based on information system alone but also image or its reputation. Advertisement, expert ranks and friend or family opinion could affect user perception against information system products.

\section{RESEARCH METHODOLOGY}

\section{A. Research Methodology}

The research was a descriptive research. The methodology used was a descriptive survey and explanatory survey. Information surveyed from part population (respondent sample) was collected directly from the site empirically in order to find out about opinion of some population against research objects..

\section{B. Object Reserch}

Research object consisted of Information Technology service level, which measured based on Listening.Reliability,Basic service,Service design, Recovery, Surprising customers, Fair play, Team Work, Employee research,Servant leadership dimension. The subject for the research was lectured, student, and academic's staff in UPI, with sample numbers were 171 people, who were taken by simple random sampling.

\section{Data Analysis}

Data analysis performed was descriptive analysis to obtain a picture of research variables from interview, questioner and quantitative analysis. User satisfaction level measurement was performed by using customer satisfaction index, meanwhile to 
define priority of service performance improvement Important Performance Analysis approach was used.

\section{RESULT AND DISCUSSION}

As Information provider, information system technology unit had a function in produced information for user while as a service provider, this unit's function was to provide support for the end user. Effectiveness of an information system unit in provided the service would affect the success of developed information systems, where an information system was claimed success if the intensity of system utilization and user satisfaction level were increased and at the end both increasing would affect the benefits accepted by user and organization.

A service quality of an information system was determined by how big compatibility level, expectation level or performance importance of each service attribute consisted of Listening, reliability, basic service, service design, recovery, surprising customers, fair play, team work, employee research, servant leadership. The result shown that based on importance level, reliability dimension was considered as the most important dimension by the user in UPI area where average value was 4,42 meanwhile fair play had the lowest mean value which was 4,36

Reliability Dimensions were valued more important compared to another service dimension because the added value of an information system especially affected by attributes from its dimension such as information access speed, system connection quality and system access security. The faster information access, the higher connection quality so the easiness to use system information would be perceived better. The easiness system utilization with security provided would increase added value received by service users. If service factors were not able to be provided by service users, then the user would not obtain the optimum benefits, and at the end user satisfaction would be low.

A fair play dimension, related to the ability of the ICT service units to understand user problem and acted on behalf customer importance, and gave personal attention to customer and had comfort office hours. Even though this dimension was considered as the lowest on the importance level compared to another dimension, this service attribute couldn't be ignored. Since fair play from the service provider was one of the service factors which user could feel directly and included into factors, which often valued by the user so sometimes its reflected the image of a service unit.

Based on performance level, ICT attributes service level which respondent considered had highest performance level was tangible dimension compared to another service dimensions. It could be seen on average value (3.11) of reliability dimension, meanwhile fair play dimension had the lowest performance which was (3.02).

Service quality provided by ICT service unit was defined by compatibility between importance level and performance level of attributes on each service dimension. Measurement results shown no compatibility, which achieves 100 percent. The attributes with performance close to customer expectation was an ICT staff unit, reliability dimension to the compatibility level only 73,08 percent

In total, satisfaction measurement using Satisfaction Index shown, that ICT facility's user satisfaction index was 61,96 percent. The result shown that in general the ICT service user was satisfied enough. ICT service performance considered could meet customer expectation, but this customer satisfaction index could decline and went into unsatisfied category (under $51 \%$ ) if the service ICT performance was not improved. So, service quality, improvement strategy was required to increase customer satisfaction.

Through Important Performance service, attributes could be identified; (1) should get first priority for improvement, (2) had low priority, (3) attributes should be maintained and (4) attributes with over performance. Attributes that should get main priority for improvement in this research were 1) Information. Speed access, (2) System connection quality during utilization, (3) Access security (4) UPInet physical facility's completeness, (5) Service delivery speed and customer problem solving, (6) Service hour provided by ICT Unit, and (7) ICT Staff Unit ability to understand customer requirement.

Those seven attributes should become main priority for improvement because those attributes had high importance levels, but its performance not meet the expectation of user, so it needs to be improved continuously. For example, information access speed should be improved. Currently, the maximum access speed was 384/64 KBPS, to meet customer expectation. The speed could be improved into 1024/128 KBPS. One of the alternative solutions to improve speed access was access service broad band technology with Asymmetric Digital Subscriber Line (ADSL) technology.

Improvement the system connection quality also became main priority, which should be performed, since this attribute was valued by the customer as an important attribute. Utilization of media fiber-optic technology to improve access quality could become an improvement alternative. Meanwhile to improve system access security, ICT system in UPI within captive portal form could reduce the possibility of user facing a cyber crime. Captive portal was a router machine or gateway that protected or not allowed the traffic until the user did registration/authentication.

UPI net was one of the access places, which used by the respondent for internet access so physical facility's completeness in UPI net was one of the services attributes that considered important by the user so the performance should be improved. Performance of physical facilities in UPInet could be increased by additional server, net screen and data center. The additional of these facilities would directly affect system quality and information. The second way was by adding supporting physical facilities that could increase customer satisfaction during accessed the service such as waiting room, access room, park lot, and other supported physical facilities. .

Service delivery speed and customer problem handling also became one of the service's attributes from responsiveness dimension which importance level was considered high by the user but the performance was low. Service delivery speed 
of a unit ICT, was considered low. One of the reasons was a limitation on a staff number of ICT unit. Currently, ICT unit had 49 human resources only (10 people had an IT education background) and should serve 104 study program or academic service unit and almost 20 thousands students users not included lecture and other academic's staff. So, added human resources, especially the one with education background in IT, was one of the problem solutions.

The ability of ICT Staff Unit to understand the customer's need was one of the attribute's service, empathy, which considered important by the user but the performance was considered low. Low user satisfaction on this attribute could affect image of the unit service, because the ability to understand customer's need was attributes, which could be felt directly by the user so often used by the user to measure the whole service quality. Based on explanation above, to improve user satisfaction, a continuous improvement of service attributes should be performed by considering priority scale so the improvement process could be worked effectively and efficient.

Service attributes. Performance could increase through improvement of physical facilities, human resources and service procedures. Physical facilities formed service attributes from tangible dimension, so to increase the quality of its attribute. Improvements of physical facilities should be performed. In general, physical facility's improvement could be performed through physical facilities planning which able to fulfill user needs both from technology point of view or quantity. But, the effort to provide sufficient physical facilities in all work units would not be effective if its rely only on the ability of ICT service units, in this case Dir ICT only, considered that ICT had to fund limitation to fulfill all physical facilities needs in all work units. So participation of each organization unit to complete the lack of physical facilities in each work unit was highly required. For example, the cooperation between ICT unit and to broad the network access by developed cable network and wireless in whole room in UPI unit area could increase user satisfaction in internet access easiness, which affected actual Internet utilization.

As a service unit, human resources function in ICT unit were not only as a system and application developer but also had function as an organization front liner which able to help users in using an information system maximal for their productivity purposes. As a service provider actor, human resources quality determined the quality of service's attributes such as reliability, responsiveness and empathy so if we would like to improve those attributes, human resources as a service provider actor also needs an improvement both quantity or quality. From quantity point of view, numbers of ICT staff, especially the one with IT educational background should be added, meanwhile from quality side, human resources development should be improved through sustainable education and training. ICT Staff unit education and training other than aimed to improve technical abilities also to make human resources of ICT unit had ability and knowledge to serve a customer. That knowledge and abilities were expected could form an attitude with customer orientation, which was an attitude to fulfill user expectation and firmed to fulfill the expectation that shown from planning process and their programs.

The commitment to serve the customer was not only formed from available facilities but also was supported by organization structure and culture. It's about time that ICT service unit had a customer-oriented structure, meant that organizational function which served a customer was accommodated. Functions such as research and development (collect, process, and database update), program, communication and public relation, was included in ICT service unit organizational structure.

ICT Service unit also should have customer oriented cultures. Cultures mentioned here was working culture, organization culture that growth and developed based on valued dig out from organization philosophy. For example customer oriented culture were cultures of serving, proactive, cooperation in a program with purpose to identify customer wishes and consistently measured customer satisfaction, designed the service based on customer's expectation and communicated in effective way.

\section{CONCLUSION AND SUGGESTION}

\section{A. Conclusion}

1. Based on importance level, ICT service attributes tangible dimension considered as the most important dimension by Information System service user in FPEB and empathy dimension was considered as the most not important one.

2. Based on performance level, ICT service attributes that received by respondent, tangible dimension considered had highest performance compared to another service dimension, meanwhile assurance dimension had lowest performance average value.

3. Satisfaction index of ICT service user in FPEB UPI was 61,96 percent. The result shown that in general the ICT service users were satisfied enough meanwhile the measurement of each service dimension shown that reliability dimension had a performance that close with user expectation, which was 73,08 percent.

4. To increase the ICT service user satisfaction some improvements were required with main priority in attributes of (1) Speed to access the information, (2) System connection quality during utilization, (3) Security access, (4) UPInet physical facilities completeness, (5) Speed in provide service and handled customer problem (6) Service hour provided by ICT unit and (7) ICT unit staffs ability to understand customer needs.

\section{B. Suggestion}

1. Physical facilities improvement to increase performance of tangible dimension by doing physical facilities planning procurement which able to full fill the user needs both from technologies quality or quantity point of view. 
2. Improving human resources quality to improve the performance of reliability, responsiveness and empathy dimension, through sustainable education and trainings to create human resources with ability and technical knowledge and owned customer oriented attitude.

3. Commitment to serve the customer must be supported by organizational structure which accommodate organization function that served the customer.

4. Organization culture development with customer oriented culture such as serving culture, pro-active, and cooperative.

\section{REFERENCES}

[1] Jogiyanto HM, Akt, MBA, Phd, (2007), "Sistem Informasi Keperilakuan", Penerbit Andi, Jogjakarta.

[2] Kotler,Keller, 2016, Marketing Management, 15e th edition, Prentice Hall International Inc., New Jersey

[3] Zeithaml, Valarie A.,1998, "Consumer Perceptions of Price, Quality, and Value: A Means-End Model and Synthesis of Evidence", Journal of Marketing, Vol. 52, July, pp. 2-22.

[4] De Lone and McLean (2003), The Lone and Mc lean Model Of Informastion Systems Sucsess : A ten Year Up Date, Journal Of Management Information system, Spring 2003 vol 19 pp 9-30
[5] Fandy Tjiptono, (2008), Service Management : Mewujudkan Layanan Prima, Penerbit Andi Jogjakarta.

[6] Lewis \& Booms, 1983, the marketing aspect of service quality, in berry, L Shostack, G,\& upahG (eds), Emerging prespectives on service marketing (pp.99-107), Chicago LL; Amaerican Marketing Assosiation

[7] A. Parasuraman, Valarie A. Zeithaml, and Leonard L. Berry, "A Conceptual Model of Service Quality and Its Implications for Future Research," Journal of Marketing (Fall 1985), pp. 41-50. Reprinted by permission of the American Marketing Association.

[8] Garvin (1987) Competing on eight dimension of quality , Harvard Business review 65 (nov-dec) 101-109

[9] DeLone\&McLean 1992 Information system sucsess: the quest for the dependent variable, Journal Information System Research page 60-95

[10] Jogiyanto HM, Akt, MBA, Phd, (2007), “ Model Kesuksesan Teknologi Sistem informasi, Penerbit Andi, Jogjakarta.

[11] Petter, DeLone and McLean (2008) Measuring Information system Sucsess, Model, Dimensions, measure and Interrlerationship, European Journal of Information system (2008) 17 PP 236-263

[12] Swanson 1974 , Management Information system:appreciation and involment, Journal of Management Science Vol 21 issue 2 P 178-188

[13] Leonard L. Berry, Kathleen Seiders, and Dhruv Grewal (2002), understanding service convinience, Journal of Marketing July $2002 \mathrm{vol}$ 66 no 3 PP 1-17

[14] Venkatesh Shankar, Janet Parish, Susan Cadwallader, and Thomas Dotzel (2006), Creating new market through service inovation , 56 MIT Sloan Management Review Winter 2006 